\title{
Encantamento do Cliente: Proposição de uma Escala para Mensuração do Constructo
}

\author{
Stefânia Ordovás de Almeida \\ Walter Meucci Nique
}

\section{RESUMO}

Apesar de o grande número de publicações que dão destaque à satisfação do cliente, a compreensão do que ocorre com ele, quando experiência um sentimento que vai além da satisfação na avaliação pós-consumo, ainda é incipiente. O fato de vivenciar esse sentimento gera um estado emocional profundamente positivo para com a experiência de compra ou consumo, que é conhecido como encantamento do cliente. A despeito da importância desse constructo no estudo do comportamento do consumidor, há uma carência de abordagens sobre o tema. Nesse sentido, o objetivo maior deste trabalho é propor e testar uma escala que meça o encantamento do cliente na avaliação pósconsumo, levando em conta as dimensões do constructo e seus comportamentos subseqüentes. Para tanto, utilizaram-se três estudos sucessivos: os dois primeiros objetivaram purificar a escala proposta; o terceiro procedeu também à sua validação. Os resultados apontam a existência de validade de conteúdo, de unidimensionalidade, de confiabilidade, de validade convergente e de validade discriminante para as dimensões do constructo estudado. Considerações finais discutem os achados do estudo, assim como sugestões para a continuidade das pesquisas sobre o tema.

Palavras-chave: comportamento do consumidor; satisfação do cliente; encantamento do cliente; desenvolvimento de escalas.

\begin{abstract}
Regardless of the great number of academic researches giving prominence to the customer satisfaction, the understanding of what happens to the customer when he/she experiences something beyond satisfaction in post-consumption experience is still incipient. Going beyond satisfaction engenders a deeply positive emotional state regarding the experience of buying or consuming, which is known as customer delight. Although the importance of this construct in the consumer behavior studies, there is still a gap in the understanding about the theme. In this sense, the main goal of this research is to propose and test a scale to measure customer delight, considering the dimensions of the construct and its post-consumption evaluation. Towards such a goal, three consecutive studies were conducted, the first two finetuning the scale and the third performing construct validation. Results suggest content validity, unidimensionality, reliability, convergent validity and discriminant validity of the construct's dimensions. Concluding comments reflect upon the findings and highlight academic and managerial implications for the field, and suggestions for future studies on customer delight are discussed.
\end{abstract}

Key words: consumer behavior; customer satisfaction; customer delight; scale development. 


\section{INTRODUÇÃO}

Os estudos sobre comportamento do consumidor têm evoluído consideravelmente nas últimas décadas e, em função disso, os aspectos cognitivos e afetivos desse comportamento têm sido amplamente discutidos e estudados (Oliver, 1997). Mesmo com esse cenário favorável, pouco se estudou até hoje o que tange ao encantamento do cliente, seja na literatura sobre psicologia, seja na literatura que versa acerca do comportamento do consumidor (Astic \& Muller, 1999; Oliver, Rust, \& Varki, 1997; Rust \& Oliver, 2000). O termo encantamento aparece na literatura de psicologia como uma emoção advinda, geralmente, de uma combinação de outras emoções (Russell, 1980). Na literatura sobre comportamento do consumidor, o encantamento do cliente começou a aparecer como rótulo, um termo para designar um grupo de consumidores que estivesse vivenciando altos níveis de satisfação e de prazer com a experiência de consumo (Westbrook \& Oliver, 1991).

Nesse sentido, pesquisas com o objetivo não apenas de compreender o constructo, mas também de diferenciá-lo da satisfação, tiveram início na última década, quando renomados autores na área de satisfação, como, por exemplo, Mano e Oliver (1993), Westbrook e Oliver (1991) e Kumar (1996), investigaram a possibilidade de que pudesse haver um estado emocional surpreendentemente agradável, além do estado de satisfação. Abriu-se, assim, novo campo de investigação dentro do escopo de estudos acerca do comportamento do consumidor.

A despeito das iniciativas descritas, os estudos realizados, até o presente momento, sobre o tema foram experimentos com o intuito de distinguir satisfação de encantamento (Kumar, 1996); surveys que quiseram hipotetizar um modelo teórico (Oliver et al., 1997); ou ainda modelos matemáticos acerca da viabilidade do encantamento como estratégia estruturada por parte das organizações (Biyalogorsky, Gerstner, \& Libai, 2001; Rust \& Oliver, 2000). Assim, não houve, no estudo dos autores citados, o teste de escala completa que permitisse avaliar as dimensões que compõem o encantamento do cliente. Neste sentido, Oliver et al. (1997) enfatizam que futuros estudos devem privilegiar a compreensão do domínio semântico do encantamento, por meio do desenvolvimento de medidas para mensuração do constructo, com o uso de escalas multi-item. Dessa forma, devido à carência de medidas válidas, confiáveis e fidedignas, que possam mensurar este resultado emocional pós-consumo, que é o encantamento do cliente (Rust \& Oliver, 2000), o objetivo deste trabalho é propor e testar uma escala para mensuração do constructo e seus resultados comportamentais no processo de avaliação pós-consumo. 
Para tanto foi realizada primeiramente uma pesquisa de natureza exploratório/ qualitativa, buscando compreender o constructo e gerar itens para uma escala de mensuração. Posteriormente, foi realizada uma pesquisa quantitativa/descritiva, por meio de três estudos: os dois primeiros tinham como objetivo apenas a purificação das medidas, com sucessivas aplicações da escala a amostras distintas; o terceiro também quis validar a escala por meio dos critérios de ajuste do modelo, de unidimensionalidade, de confiabilidade, de validade convergente e de validade discriminante, devidamente atribuídos ao instrumento. A validade de conteúdo foi preocupação constante durante o estudo.

Assim, este trabalho compreende a revisão teórica dos aspectos que envolvem o encantamento do cliente e a descrição dos procedimentos metodológicos utilizados no estudo. A explanação acerca das análises realizadas e dos resultados encontrados busca pormenorizar os achados da pesquisa como um todo, dando embasamento à construção das considerações finais que concluem o trabalho.

\section{Compreendendo o Encantamento do Cliente}

Para se compreender o encantamento do cliente o embasamento deve vir dos primeiros estudos realizados sobre o tema, ainda na área da psicologia. Neste campo de estudos, o encantamento começou a ser definido como emoção, formada a partir da combinação de outras emoções. Assim, para Izard (1977), interesse, alegria e surpresa seriam as emoções preditoras do encantamento. Segundo Plutchik (1980), o encantamento seria uma emoção de terceira ordem dada pela combinação de alegria e surpresa. Para Russell (1980), o encantamento é caracterizado pela combinação de prazer e ativação.

A partir dessas pré-definições da área da psicologia, o encantamento do cliente pôde então ser definido na área de comportamento do consumidor como "uma emoção, caracterizada por altos níveis de alegria e surpresa, sentidos por um cliente através da empresa ou sua oferta (produto/serviço)" (Kumar, 1996, p. 9). Assim, o encantamento do cliente é definido como estado emocional profundamente positivo da experiência de compra/consumo, geralmente resultante da desconfirmação surpreendentemente positiva das expectativas (Oliver et al., 1997), ou seja, o encantamento seria caracterizado como emoção composta de aspectos cognitivos e afetivos, incluindo aqui a surpresa (Kumar, 1996). Neste sentido, Izard (1977) esclarece que mesmo os conceitos cognitivos inerentes à satisfação e, conseqüentemente, ao encantamento do cliente, como precisar, necessitar e desejar, e seus padrões de comparação, são considerados afetivos por natureza ou pelo menos como tendo um componente afetivo. Esta definição de 
encantamento do cliente, aqui apresentada, contemplada por Kumar (1996) e Oliver et al. (1997), será a adotada neste estudo.

A despeito da definição apresentada acerca do encantamento e de seus componentes formadores, vários autores e estudos que buscaram compreender a capacidade de explicação do componente afetivo nas avaliações pós-consumo esbarraram na comparação entre satisfação e encantamento, ou melhor, na diferenciação de até aonde vai a satisfação e onde começa o encantamento. Ou seja, qual é o diferencial entre esses dois resultados das experiências de consumo? Apesar de Vanhamme (2002) definir o encantamento como o nível mais alto de satisfação do cliente, este sentimento não pode ser confundido com mera satisfação, ainda que o consumidor encantado deva primeiramente estar satisfeito. Assim, abre-se espaço aqui para a verificação de alguns tópicos de diferenciação entre a satisfação e o encantamento, por meio de uma série de estudos nas áreas da psicologia e comportamento do consumidor, como se explicitam em seguida:

Afeto Positivo. Mano (1997) afirma que o afeto positivo varia em duas dimensões primárias: prazer e ativação. Logo, ambas as dimensões são vistas como complementares na formação do encantamento, uma vez que o prazer sozinho é visto apenas como afeto positivo de ativação moderada (Mano \& Oliver, 1993). Neste sentido, para Mano e Oliver (1993) e Oliver e Westbrook (1993), a diferenciação entre satisfação e encantamento dá-se basicamente no nível de ativação da resposta emocional positiva em uma experiência de consumo: sendo baixa, temos a satisfação; sendo alta, temos o encantamento.

Desconfirmação de Expectativas. Segundo Oliver (1997), as expectativas podem ser desconfirmadas de duas maneiras, na primeira, o produto/serviço pode ser melhor do que o esperado, mas não produz surpresa; na segunda, o desempenho é surpreendentemente positivo. O encantamento então poderia ser descrito como este nível de desconfirmação surpreendentemente positiva, dado através de níveis surpreendentemente positivos de desempenho percebido (Rust \& Oliver, 2000).

Surpresa Positiva. A surpresa positiva é um dos principais elementos diferenciadores entre a satisfação e o encantamento do cliente. Para Rust e Oliver (2000), as características de um produto ou serviço com capacidade de encantar são aquelas que trazem prazer inesperado ou surpresa prazerosa, ou ainda adicionam utilidade ao produto, além daquela esperada. Isto porque, segundo Anderson (1998), performance surpreendente em um atributo esperado versus performance surpreendente em um atributo inesperado terá um impacto assimétrico no encantamento do cliente. Cognitiva e emocionalmente, segundo o autor, performance positiva em atributos que não são parte do conhecimento anterior do consumidor tem maior potencial de encantamento. 
É importante notar que o papel da surpresa como amplificador das reações subseqüentes se dá através da ativação presente nela (Charlesworth, 1969 como citado em Derbaix \& Vanhamme, 2003). Assim, como resultado da avaliação de quão prazerosa ou não-prazerosa tenha sido a experiência de consumo, a emoção da surpresa é geralmente seguida por outra emoção que lhe dá tons positivos ou negativos. No caso de haver incremento do afeto positivo, tendo a surpresa causado impacto positivo na experiência de consumo, o cliente ficará encantado (Derbaix \& Vanhamme, 2003).

Envolvimento. Mano e Oliver (1993) identificaram que experiências de consumo que tenham envolvimento por parte do consumidor estão mais relacionadas ao encantamento que à satisfação. Segundo Oliver et al. (1997), em situações em que haja envolvimento por parte do consumidor e variabilidade da experiência de consumo, caso haja um nível apropriado de performance prazerosa não esperada, o encantamento poderá manifestar-se.

Consumo Utilitário x Consumo Hedônico. Para Mano e Oliver (1993), as avaliações hedônicas estariam mais próximas das experiências afetivas dos consumidores e, portanto, do encantamento do que da satisfação do cliente.

Evidências acerca da diferenciação entre satisfação e encantamento podem ser encontradas, ainda, nos estudos realizados por Westbrook e Oliver (1991) e Oliver e Westbrook (1993), os quais mostraram que consumidores que experienciaram altos níveis de alegria e de surpresa apresentavam maiores índices de intenção de recompra e maior grau de desconfirmação de expectativas. Os autores confirmaram, então, empiricamente, a existência de um estado de encantamento separado da satisfação.

Kumar (1996) também atribuiu validade discriminante aos constructos e concluiu que os efeitos do encantamento nas intenções de recompra são maiores e estão além dos efeitos da satisfação. Assim, o consumidor encantado estará mais propenso a pagar preços maiores, a ter atitudes ligadas à intenção de recompra, a tecer recomendações e a fazer boca a boca positivo (Kumar, 1996). Segundo Keiningham e Vavra (2001), consumidores encantados também passam a ignorar marcas competidoras. Desta forma, para Astic e Muller (1999), o encantamento do cliente supostamente leva à lealdade atitudinal e à retenção de clientes.

Percebe-se, assim, que o encantamento do cliente caracteriza-se como avaliação pós-consumo única, não podendo ser confundido com uma única emoção positiva extrema, sendo que é uma combinação dos aspectos afetivos e cognitivos descritos. Ou seja, o encantamento é justamente uma função da performance surpreendentemente positiva, que leva à ativação do afeto positivo em uma dada experiência de consumo (Rust \& Oliver, 2000). Por esta razão, o encantamento 
do cliente também não pode ser confundido com extrema satisfação do cliente, uma vez que não é apenas a intensidade da satisfação que proporciona a existência do encantamento, ainda que este seja importante pré-requisito, uma vez que existem outros componentes, já descritos anteriormente, que diferenciam a satisfação do cliente do encantamento do cliente enquanto avaliação pós-consumo.

\section{Método}

Primeiramente o processo de desenvolvimento da escala será apresentado, considerando suas fases exploratória e descritiva. Por fim, dar-se-á atenção ao processo de validação. Esses procedimentos foram realizados em consonância com os encaminhamentos de Churchill (1979) acerca do tema.

\section{Desenvolvimento da Escala para Mensuração do Encantamento - Etapa Exploratória}

A fase exploratório/qualitativa do processo de desenvolvimento de escala foi responsável pela especificação do domínio do constructo estudado e pela geração de itens. Primeiramente foi realizada uma investigação bibliográfica através do estudo de inúmeros trabalhos das áreas de marketing e psicologia. Cabe ressaltar ainda que foram realizados contatos via e-mail com os professores Roland Rust da University of Maryland e Richard Oliver da Vanderbilt University. O conhecimento sobre o tema de pesquisa, adquirido até então, serviu de base para que se pudesse elaborar um roteiro adequado para as entrevistas em profundidade, além de permitir a visualização de possíveis itens para a escala.

Posto isso, 30 consumidores foram ouvidos a respeito de suas experiências de consumo altamente satisfatórias. A escolha dos entrevistados deu-se primeiramente através da seleção de consumidores que se disseram altamente satisfeitos para com algum produto ou serviço, uma vez que alto nível de satisfação é requisito para a formação do encantamento. Solicitou-se a esses consumidores que relatassem sua experiência de consumo, para que se pudesse verificar a existência de encantamento. Feito isso, foram 20 os consumidores cujos relatos se encaixaram na formulação teórica acerca do tema, de acordo com a percepção do pesquisador sobre a existência de encantamento nas experiências relatadas. Esses consumidores foram, então, convidados a participar das entrevistas em profundidade.

Para a construção da escala, os itens de mensuração vieram de distintas fontes. Aqueles incumbidos da mensuração da surpresa positiva foram retirados da escala 
DES II (Differential Emotions Scale) de Izard (1977). Os itens que deveriam mensurar as demais dimensões foram adaptados principalmente dos estudos de Kumar (1996), Oliver et al. (1997), Rust e Oliver (2000) e Keiningham e Vavra (2001), com o respaldo das entrevistas em profundidade. Estes itens passaram por um processo de versão para o português, levando-se em consideração a distinção da pesquisa aqui apresentada em relação aos estudos originais. Uma vez feita a versão, dois acadêmicos de marketing avaliaram a sua compreensão.

Seguindo sugestões de DeVellis (1991), os itens definidos para a escala, após os procedimentos exploratórios explicitados, foram analisados por três experts em marketing no Brasil. Feitos os ajustes sugeridos por esses nos indicadores, $o$ processo de confirmação final da estrutura teórica deu-se através de uma conversa face-to-face com o professor Roland Rust da University of Maryland. Assim, a primeira versão da escala construída era composta por 40 itens, que poderiam compor o constructo encantamento do cliente através de cinco grandes dimensões, quais sejam: aspectos cognitivos, aspectos afetivos, surpresa positiva, percepções de preço e propensão à recomendação e recompra. Além destes itens a escala possuía, ainda, um item âncora de avaliação geral da experiência de consumo denominado "Eu fiquei encantado com o resultado desta experiência".

\section{Desenvolvimento da Escala para Mensuração do Encantamento - Etapa Descritiva}

A etapa descritiva do processo de desenvolvimento da escala de encantamento teve início com um pré-teste do instrumento de coleta de dados realizado com dez pessoas da mesma população do estudo, buscando identificar variáveis em que houvesse problemas de compreensão/interpretação. A partir disso, foram feitos pequenos ajustes na escala.

Com o objetivo de testar, purificar e validar a escala, três reaplicações sucessivas, com três diferentes amostras da mesma população foram utilizadas. A população era composta de estudantes universitários de cursos de graduação em Administração de três diferentes universidades gaúchas. A primeira e a segunda amostra, usadas somente para purificar a escala, tinham 146 e 129 respondentes, respectivamente; a terceira, que deveria também se prestar à validação, tinha 240 respondentes. Com relação às amostragens, verificou-se que $53 \%$ dos respondentes do primeiro estudo, $38,8 \%$ e $56 \%$ dos respondentes do segundo e do terceiro estudo, respectivamente, afirmaram ter tido a experiência causadora do encantamento até seis meses antes da pesquisa. Os respondentes também foram indagados se estavam referindo-se à experiências ocorridas com produtos ou serviços, sendo que a taxa de respondentes que analisou experiências com produtos foi de $81 \%$ no primeiro estudo, $92 \%$ e $71 \%$ no segundo e terceiro estudos, respectivamente. 
Os procedimentos utilizados para testar e purificar a escala foram baseados nas proposições de DeVellis (1991), em que a análise fatorial exploratória (EFA), as comunalidades dos itens, a medida de confiabilidade através do Alfa de Cronbach e as conseqüentes correlações item-item e item-total foram utilizadas, além de medidas descritivas básicas. O software utilizado foi o SPSS 10.0. Além disso, seguindo as recomendações de Hair, Anderson, Tatham e Black (1998), foram examinados os outliers univariados através do teste do coeficiente $Z$ e, apenas na terceira coleta de dados, foi necessário retirar oito outliers da amostra.

A coleta de dados foi feita entre março e maio de 2003 pelo pesquisador nas salas de aula e os próprios respondentes preencheram o questionário. A recomendação dada aos participantes para responder ao questionário era a de levar em consideração uma experiência de consumo altamente satisfatória que tivessem experimentado, considerando-se o foco do estudo. Os itens da escala de encantamento estavam baseados em uma escala de sete pontos tipo Likert (discordo totalmente-concordo totalmente).

\section{Validação da Escala para Mensuração do Encantamento}

Para a validação da escala proposta foram utilizados dois procedimentos, a validade de conteúdo e a validade de constructo, sugeridas por DeVellis (1991). A escala a ser validada possuía 23 itens divididos em cinco dimensões: aspectos afetivos, aspectos cognitivos, surpresa positiva, propensão à recomendação e recompra e personalização; além do item de avaliação geral da experiência de consumo. A validação do constructo deu-se através da submissão das cinco dimensões como cinco diferentes modelos de mensuração da análise fatorial confirmatória (CFA), utilizando o software AMOS 4.0. A validade de conteúdo foi atingida pela análise lógica (Peter, 1981).

Anteriormente ao processo de validação, analisou-se a existência de missing values, sendo os poucos casos encontrados substituídos pela média da variável (Hair et al., 1998), e a inexistência de outliers multivariados (medidos através da distância de Mahalanobis $\mathrm{D}^{2}$ ). Pequenos problemas de normalidade foram verificados e eliminados de acordo com os critérios sugeridos por Kline (1998).

\section{Resultados do Processo de Desenvolvimento da Escala de ENCANTAMENTO}

Para que se pudesse atingir a validade de conteúdo e de constructo, objetivos maiores deste estudo, a presente etapa se faz necessária no sentido de purificar 
a escala, eliminando os itens redundantes ou com baixo poder de explicação, buscando, assim, melhorar as suas propriedades psicométricas (Finn \& Kayande, 2004). As análises fatoriais exploratórias realizadas em todos os estudos tiveram como método a extração de componentes principais sobre a matriz de correlações, sendo que foi efetuada a rotação ortogonal Varimax (DeVellis, 1991). Este método é considerado apropriado, quando se busca redução do número de itens de uma escala (Finn \& Kayande, 2004). O critério de corte para retenção dos fatores foi o de autovalor maior ou igual a 1 (Hair et al., 1998). A medida Kaiser-Meyer-Olkin (KMO) foi utilizada para indicar a adequação dos dados à análise fatorial, sendo que quanto maior o valor resultante (mais próximo de 1), melhor será a adequação. O teste de esfericidade de Bartlett também foi utilizado e, para todas as análises realizadas, rejeitou-se a hipótese nula de não haver correlação significativa entre as variáveis da amostra estudada.

Valores aceitáveis para cada uma das demais análises são balizados pela literatura. Segundo recomendações de Hair et al. (1998), itens com comunalidades (percentagem da variância do item restituída pela solução final) inferiores a 0,5 devem ser retirados. O Alfa de Cronbach será considerado aceitável a partir de 0,60, de acordo com as recomendações do autor para estudos exploratórios. Para as correlações item-total um mínimo de 0,50 foi considerado (DeVellis, 1991; Hair et al., 1998). O critério de corte para a correlação item-item máxima entre duas variáveis foi de 0,80 (Kline, 1998).

\section{Primeiro Estudo}

Levando-se em consideração os procedimentos explicitados anteriormente, a primeira versão da escala, aplicada à primeira amostra e submetida à EFA, é apresentada a seguir. Nove fatores são responsáveis por representar $67,32 \%$ da variância explicada, sendo que a medida KMO de adequação da amostra ficou em 0,862 .

Segundo Hair et al. (1998), o mínimo de carga fatorial que uma variável deve carregar em algum fator para ser significante em uma amostra em torno de 200 respondentes é de 0,4 , valor adotado neste estudo. Para a realização dos testes de confiabilidade e de correlações alguns dos indicadores apresentados foram reagrupados de acordo com sua coerência conceitual e suas cargas fatoriais. A Tabela 1 apresenta os resultados da EFA, por meio de suas cargas fatoriais e suas comunalidades, anteriormente à realização desses ajustes. 


\section{Tabela 1: Estrutura Fatorial Inicial do Primeiro Estudo}

\begin{tabular}{|c|c|c|}
\hline & Fator 1 - Itens & Carga Com \\
\hline V11 & Essa experiência me trouxe felicidade & 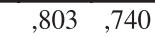 \\
\hline V3 & Esse produto/serviço me transmitiu sensações positivas & 698, 736 \\
\hline V7 & Essa foi uma experiência estimulante & 679, 698 \\
\hline V15 & Essa experiência me trouxe satisfação pessoal & 670, 662 \\
\hline V2 & Essa experiência me trouxe prazer & 666, 743 \\
\hline V1 & Essa experiência me trouxe alegria & 654, 758 \\
\hline V8 & Essa foi uma experiência fascinante & 652, 710 \\
\hline V17 & Essa experiência foi atraente para mim & 608, 707 \\
\hline V10 & Esse produto/serviço realizou um sonho que eu tinha & 600,602 \\
\hline V5 & Tenho uma identificação pessoal com esse produto/serviço & 592, 676 \\
\hline V12 & Essa experiência me fez sentir importante & ,564, 723 \\
\hline \multirow[t]{2}{*}{ V4 } & Essa experiência de consumo foi uma das mais marcantes que já tive & ,356 600 \\
\hline & Fator 2 - Itens & Carga Com \\
\hline V23 & Esse produto/serviço teve uma performance excepcional & ,794,744 \\
\hline V24 & Essa experiência de consumo atendeu plenamente os meus desejos & 755 728 \\
\hline V19 & Essa experiência superou todas as minhas expectativas & 680,670 \\
\hline V22 & A qualidade desse produto/serviço é superior a das demais existentes & 677, 643 \\
\hline V21 & $\begin{array}{l}\text { Nessa experiência todos os atributos que poderiam ser satisfatórios foram mais do que } \\
\text { satisfatórios }\end{array}$ & 655, 691 \\
\hline V25 & Esse produto/serviço teve grande valor para mim & 632,562 \\
\hline V18 & Recebi um produto/serviço padrão & 481, 691 \\
\hline \multirow[t]{2}{*}{ V26 } & Recebi mais do que o esperado nessa experiência de consumo & ,424,608 \\
\hline & Fator 3-Itens & Carga Com \\
\hline V30 & Esse produto/serviço teve uma performance excepcional & ,749,651 \\
\hline V29 & Eu fiquei positivamente admirado com essa experiência de consumo & 692, 799 \\
\hline V16 & Essa experiência foi irresistível para mim & 673, 736 \\
\hline V14 & Eu me senti realizado com essa experiência de consumo & 647, 790 \\
\hline V13 & Essa experiência me fez sentir especial & 597, 754 \\
\hline \multirow[t]{2}{*}{$\mathrm{V} 28$} & Eu me surpreendi positivamente com essa experiência de consumo & ,537,711 \\
\hline & Fator 4 - Itens & Carga Com \\
\hline V32 & Eu pretendo recomprar esse produto/serviço no futuro & ,795, 723 \\
\hline V33 & Eu recomendaria esse produto/serviço para um amigo & 735, 803 \\
\hline V34 & Após essa experiência de consumo tive vontade de elogiar a empresa/funcionário & 672, 726 \\
\hline \multirow[t]{2}{*}{ V31 } & $\begin{array}{l}\text { Eu sou propenso a fazer comentários positivos sobre esse produto/serviço para outras } \\
\text { pessoas }\end{array}$ & 605 609 \\
\hline & Fator 5 - Itens & Carga Com \\
\hline V6 & Se eu não tivesse comprado esse produto/serviço teria me sentido frustrado(a) & 694,679 \\
\hline V36 & $\begin{array}{l}\text { Considero que tenho um relacionamento com essa empresa de quem comprei o } \\
\text { produto/serviço }\end{array}$ & 653,585 \\
\hline V9 & Esse produto/serviço foi feito sob medida para mim & ,535, 570 \\
\hline \multirow[t]{2}{*}{$\mathrm{V} 35$} & Sou um cliente mais fiel/leal após essa experiência & ,511,662 \\
\hline & Fator 6 - Itens & Carga Com \\
\hline V37 & O preço foi variável decisiva na escolha desse produto/serviço & ,834,758 \\
\hline \multirow[t]{2}{*}{ V27 } & Houve flexibilidade para atender às minhas necessidades nessa experiência de consumo &, $543 \quad 530$ \\
\hline & Fator 7 - Itens & Carga Com \\
\hline V39 & $\begin{array}{l}\text { O preço desse produto/serviço influenciou o meu grau de satisfação para com } \\
\text { a experiência de consumo }\end{array}$ & 698 ,577 \\
\hline \multirow[t]{2}{*}{$\mathrm{V} 40$} & Considero que paguei um preço justo por esse produto/serviço & ,597,573 \\
\hline & Fator 8 - Itens & Carga Com \\
\hline \multirow[t]{2}{*}{ V38 } & Em relação a minha capacidade de compra o preço desse produto/serviço não é muito caro & ,741,727 \\
\hline & Fator 9-Itens & Carga Com \\
\hline V20 & Recebi um atendimento personalizado &, $678 \quad 719$ \\
\hline
\end{tabular}


De acordo com as explanações anteriores, as variáveis V13, V14 e V16 foram agrupadas junto ao Fator 1, pois possuíam cargas altas nesse fator $(0,459 ; 0,501$ e 0,419 , respectivamente) e maior relação teórica com o fator. Pela mesma razão, o item V35 foi agrupado junto ao Fator 4, com carga de 0,463. Outros dois itens foram reagrupados, devido à correlação conceitual e por estarem sozinhos em um fator. Assim, a variável V38 foi agrupada ao Fator 7 e a variável V20 ao Fator 2.

Feitas as análises de confiabilidade e de correlações e, levando-se em consideração o resultado da EFA, decidiu-se pela eliminação de algumas variáveis. Assim, no Fator 1 eliminaram-se as variáveis V4 - carga fatorial: 0,356; V5 e V10 por entender-se que essas duas variáveis poderiam ser confusas na percepção do respondente. Na análise do Fator 2, três itens apresentaram baixas correlações item-total: V18, V20 e V26 com correlações de 0,2892; 0,4423 e 0,4822, respectivamente. Pode-se perceber também que os itens V18 e V26 já tinham apresentado cargas inferiores a 0,5 na análise fatorial. Assim, esses dois itens foram retirados; porém, devido à percepção de que a padronização, medida pelo item V18, não estava sendo bem compreendida na sua relação com o encantamento, inseriu-se novo item denominado "recebi um produto/serviço personalizado" com o mesmo código de variável para o segundo estudo.

No Fator 5 o Alfa de Cronbach ficou em 0,5964, os indicadores V6, V9 e V36 apresentaram correlações item-total insuficientes $(0,4488 ; 0,3808$ e 0,3892, respectivamente). Uma vez que os itens não estavam associados fortemente (carga acima de 0,4) a nenhum outro fator da escala, e devido a apresentarem-se confusos quanto à sua necessidade para a formação do encantamento, optou-se por eliminá-los. Os itens referentes ao Fator 6 apresentaram comportamento totalmente impróprio na análise de confiabilidade, tendo correlações item-total extremamente baixas e negativas. Assim, decidiu-se pela exclusão do item V27 e pela manutenção do item V37, para verificar se haveria mudança no seu comportamento na próxima coleta de dados.

O Fator 7 foi outro que obteve desempenho insatisfatório, apresentando um Alfa de Cronbach inferior ao desejado (0,5164), e correlações item-total bastante baixas $(0,3614 ; 0,3950$ e 0,2442, respectivamente para V38, V39 e V40). Apesar dos resultados desfavoráveis, esse bloco foi mantido, devido à crença de que apresentaria um comportamento mais confiável nas demais coletas. A grafia do item V38 que foi alterada para 'em relação a minha capacidade de compra o preço desse produto/serviço é muito caro' para o segundo estudo, buscando melhor interpretação por parte dos respondentes. 
Os valores do Alfa de Conbach para cada um dos fatores após as modificações feitas foram: Fator 1: 0,9303; Fator 2: 0,8542; Fator 3: 0,8125; Fator 4: 0,8343; Fator 5: não houve itens restantes; Fator 6: somente um item restou; Fator 7: 0,5164. Assim, realizou-se uma nova análise fatorial e nenhum item apresentou carga fatorial ou comunalidade abaixo de 0,5. A nova estrutura fatorial possuía 31 variáveis, divididas em seis fatores, respondendo por uma variância total explicada de $66,327 \%$, sendo que a medida KMO ficou em 0,871 .

\section{Segundo Estudo}

A escala, com as alterações descritas e aplicada a uma segunda amostra, apresentou uma estrutura fatorial composta de cinco fatores, após três itens serem realocados, devido ao critério de definição conceitual. A EFA apresentou uma variância total explicada de 67,191\% sendo que a medida KMO também se mostrou adequada, tendo um valor de 0,861 para a análise em estudo. Somente um fator, composto pelas variáveis V37, V38 e V39, apresentou soluções impróprias de acordo com as análises realizadas, tendo um Alfa de Cronbach de 0,3848 e correlações fora dos padrões estabelecidos. Dessa forma, seguindo as recomendações de Churchill (1979), voltou-se à análise das entrevistas em profundidade, buscando ainda encontrar o ajuste acerca das questões de preço. Assim, a variável V37 foi reescrita para "o preço desse produto/serviço me estimulou a comprá-lo" e a variável V38 foi excluída, por permitir interpretações dúbias. Fora essas, não foi feita nenhuma alteração na escala com relação ao estudo anterior.

\section{Terceiro Estudo}

A análise de dados resultante da terceira coleta, com a terceira versão da escala aplicada à terceira amostra, apontou uma estrutura fatorial composta por seis dimensões, respondendo por uma variância total explicada de $64,52 \%$. A medida KMO também se mostrou adequada, apresentando um valor de 0,874 para a análise em exame.

Para a análise dos resultados, conduziu-se a EFA no início do processo e compararam-se seus resultados com aqueles da análise de consistência interna e correlações item-item e item-total, realizando-se todos os procedimentos 
novamente, cada vez que uma variável era retirada. Assim, no final de todas as análises realizadas, decidiu-se pela eliminação dos seguintes itens: V40 (itemtotal de 0,3795 e comunalidade de 0,457), V35 (item-total de 0,3521), V17 (comunalidade de 0,369 e carga fatorial de 0,423), V34 (carga fatorial de 0,416 e item-total de 0,4364), V13 (carga fatorial de 0,490 e item-item de 0,8194 com o item V12) e V16 (item-total =0,3862).

Os itens relativos à mensuração da percepção de preço não possuíam amplo suporte na literatura e foram inseridos na análise devido à sua aparição constante nas entrevistas em profundidade (Rossiter, 2002). Tendo-se percebido a sua pouca aderência à escala e, conseqüentemente, ao constructo estudado, houve a crença de que a percepção de preço não estava correlacionada à existência do encantamento. A necessidade de mudança da grafia das questões acerca de preço, desde a primeira coleta de dados, e os índices ruins apresentados por essas variáveis, também denotaram a sua pouca correlação para com o constructo. Assim, apesar de o fator de percepção de preço final (variáveis V37 e V39) ter apresentado no presente estudo um Alfa de Cronbach de 0,6996, valor aceitável em estudos exploratórios, e uma correlação item-total de 0,5381, optou-se pela retirada do fator.

Com a retirada do fator de percepção de preço, uma nova EFA foi realizada e a estrutura fatorial final apresentou cinco fatores, sendo que as variáveis V31, V32, e V33, pertencentes à dimensão de propensão à recomendação e recompra, separaram-se das variáveis de cognição com as quais estavam agrupadas anteriormente, formando uma estrutura fatorial mais lógica do ponto de vista teórico. Os itens V20 e V18 apresentaram-se sozinhos em um fator que passou a ser chamado de dimensão de personalização. A estrutura fatorial final da escala a ser validada, apresentando para a medida KMO um valor de 0,887 , e respondendo por uma variância total explicada de $68,71 \%$, seguida de suas comunalidades, médias e desvios-padrão, é apresentada na Tabela 2 . 


\section{Tabela 2: Estrutura Fatorial Final do Terceiro Estudo}

\begin{tabular}{|c|c|c|c|c|c|c|c|}
\hline Itens & \begin{tabular}{c|c|} 
Fator \\
1
\end{tabular} & $\begin{array}{c}\text { Fator } \\
2\end{array}$ & $\begin{array}{c}\text { Fator } \\
3\end{array}$ & $\begin{array}{c}\text { Fator } \\
4\end{array}$ & $\begin{array}{c}\text { Fator } \\
5\end{array}$ & Com & $\begin{array}{l}\text { Médias } \\
\text { /Dp }\end{array}$ \\
\hline V1 Essa experiência me trouxe alegria &, 824 & & & & & ,763 & $5,6 / 1,3$ \\
\hline V7 Essa foi uma experiência estimulante & ,809 & & & & &, 740 & $5,3 / 1,4$ \\
\hline V3 Esse produto/serviço me transmitiu sensações positivas & 806 & & & & &, 740 & $5,8 / 1,2$ \\
\hline V2 Essa experiência me trouxe prazer & ,796 & & & & & 677 & $5,6 / 1,3$ \\
\hline V11 Essa experiência me trouxe felicidade & ,793 & & & & & 653 & $5,3 / 1,3$ \\
\hline V14 Eu me senti realizado com essa experiência de consumo & 669 & & & & & ,629 & $5,2 / 1,4$ \\
\hline V15 Essa experiência me trouxe satisfação pessoal & 667 & & & & & ,622 & $5,5 / 1,4$ \\
\hline V25 Esse produto/serviço teve grande valor para mim & 653 & & & & &, 596 & $4,4 / 1,7$ \\
\hline V8 Essa foi uma experiência fascinante & ,638 & & & & & ,602 & $4,9 / 1,5$ \\
\hline V12 Essa experiência me fez sentir importante &, 612 & & & & &, 572 & $4,6 / 1,7$ \\
\hline V23 Esse produto/serviço teve uma performance excepcional & & ,812 & & & &, 772 & $5,4 / 1,3$ \\
\hline $\begin{array}{l}\text { V22 A qualidade desse produto/serviço é superior à das demais } \\
\text { existentes }\end{array}$ & &, 742 & & & &, 595 & $5,2 / 1,5$ \\
\hline $\begin{array}{l}\text { V24 Essa experiência de consumo atendeu plenamente aos meus } \\
\text { desejos }\end{array}$ & & ,738 & & & & ,689 & $6,0 / 1,2$ \\
\hline $\begin{array}{l}\text { V21 Nessa experiência todos os atributos que poderiam ser } \\
\text { satisfatórios foram mais do que satisfatórios }\end{array}$ & & ,644 & & & & ,681 & $5,01,4$ \\
\hline V19 Essa experiência superou todas as minhas expectativas & & 605 & & & &, 597 & $5,3 / 1,3$ \\
\hline V33 Eu recomendaria esse produto/serviço para um amigo & & & ,832 & & & ,792 & $6,2 / 1,1$ \\
\hline V32 Eu pretendo recomprar esse produto/serviço no futuro & & &, 820 & & &, 719 & $5,6 / 1,7$ \\
\hline $\begin{array}{l}\text { V31 Eu sou propenso a fazer comentários positivos sobre esse } \\
\text { produto/serviço para outras pessoas }\end{array}$ & & & 603 & & & 605 & $5,8 / 1,4$ \\
\hline $\begin{array}{l}\text { V30 Eu fiquei positivamente perplexo com essa experiência de } \\
\text { consumo }\end{array}$ & & & & & & ,672 & \\
\hline $\begin{array}{l}\text { V29 Eu fiquei positivamente admirado com essa experiência de } \\
\text { consumo }\end{array}$ & & & & ,702 & & , 746 & $5,3 / 1,5$ \\
\hline $\begin{array}{l}\text { V28 Eu me surpreendi positivamente com essa experiência de } \\
\text { consumo }\end{array}$ & & & &, 546 & & ,711 & $5,6 / 1,2$ \\
\hline V20 Recebi um atendimento personalizado & & & & & 875 &, 818 & $4,9 / 2,0$ \\
\hline V18 Recebi um produto/serviço personalizado & & & & &, 868 &, 812 & $4,5 / 2,0$ \\
\hline
\end{tabular}

Quando se analisam as medidas descritivas apresentadas aqui, pode-se perceber a existência de altos desvios-padrão. A compreensão para tais valores veio através da realização de uma ANOVA entre consumidores de produtos e serviços, o que comprovou existirem diferenças estatisticamente significativas nas médias dos grupos para 16 das 23 variáveis analisadas. Nesses casos, os consumidores de serviços sempre tiveram as maiores médias.

Assim, a escala observada na EFA acima é aquela apresentada para ser validada, sendo composta por 23 itens, divididos em cinco fatores, representando as cinco dimensões finais do constructo, acrescidas do item de avaliação geral da experiência de consumo já descrito anteriormente. As dimensões são descritas, a seguir, acompanhadas de seus respectivos valores para o Alfa de Cronbach: Fator 1 - Dimensão de Aspectos Afetivos (0,9179); Fator 2 - Dimensão de Aspectos Cognitivos (0,8497); Fator 3 - Dimensão de Propensão à Recomendação e Recompra (0,7735); Fator 4 - Dimensão de Surpresa Positiva (0,7725); Fator 5 Dimensão de Personalização $(0,7830)$. 


\section{Resultados da Validação da Escala de Encantamento}

Os procedimentos para validação da escala proposta, levando-se em consideração a validade de conteúdo e a validade de constructo, são apresentados aqui. A primeira já foi atingida através do rigor metodológico utilizado nas etapas de desenvolvimento e de refinamento da escala, devidamente explicitadas no método do estudo. Assim, com vistas a verificar a validade de constructo, as cinco dimensões da escala foram submetidas, como cinco diferentes modelos de mensuração, à análise fatorial confirmatória (CFA).

As informações provenientes da CFA procuram confirmar a estrutura fatorial, vinda do processo de desenvolvimento de escala. Esse método é amplamente utilizado em estudos de marketing e em campos correlatos na busca da validade de constructo (Bagozzi, Yi, \& Philips, 1991; Dunn, Seaker, \& Waller, 1994; Garver \& Mentzer, 1999; Jöreskog \& Sörbom, 1982; Steenkamp \& Trijp, 1991). Nesse sentido, os autores citados recomendam como procedimentos necessários para atingir a validade de constructo a unidimensionalidade, a confiabilidade, a validade convergente e a validade discriminante, além do critério de ajuste dos modelos de mensuração. Assim, a Tabela 3 abaixo apresenta os resultados da CFA para as cinco dimensões propostas.

\section{Tabela 3: Resultados da CFA para as Cinco Dimensões Propostas}

\begin{tabular}{lccccc}
\hline \multicolumn{1}{c}{ Medidas de Ajuste } & Afeto & Cognição & $\begin{array}{c}\text { Recomendação } \\
\text { e Recompra }\end{array}$ & $\begin{array}{c}\text { Surpresa } \\
\text { Positiva }\end{array}$ & Personalização \\
\hline Qui-quadrado $\left(\boldsymbol{\chi}^{\mathbf{2}}\right)$ & 59,145 & 8,534 & 4,745 & 6,285 & 6,980 \\
Graus de Liberdade $(\mathbf{G L})$ & 33 & 4 & 1 & 2 & 1 \\
Qui-quadrado/graus de liberdade $\left(\boldsymbol{\chi}^{\mathbf{2}} / \mathbf{G L}\right)$ & 1.792 & 2.134 & 4.745 & 3.124 & 6.980 \\
Goodness-of-fit Index $(\mathbf{G F I )}$ & 0.952 & 0.985 & 0.986 & 0.983 & 0.971 \\
Adjusted Goodness- of-fit Index (AGFI) & 0.919 & 0.944 & 0.917 & 0.950 & 0.913 \\
Tucker-Lewis Index (TLI) & 0.976 & 0.975 & 0.964 & 0.976 & 0.945 \\
Comparative Fit Index $(\mathbf{C F I )}$ & 0.983 & 0.990 & 0.988 & 0.984 & 0.945 \\
Root Mean Square Error of & 0.059 & 0.070 & 0.127 & 0.096 & 0.161 \\
Approximation (RMSEA) & & & & & \\
\hline
\end{tabular}

Método de Estimação: Maximum Likelihood.

Analisando-se os índices de ajustamento, pode-se perceber que a maioria das medidas é satisfatória. Ainda que a relação $\chi^{2} /$ GL para a dimensão de personalização seja maior do que cinco, valor máximo adequado, segundo as recomendações de Hair et al. (1998), a probabilidade do qui-quadrado ser influenciado pelo tamanho e variações da amostra é conhecida e discutida na literatura (Hair et al., 1998; Kline, 1998). Assim, Raykov e Marcoulides (2000) recomendam que outros índices de ajustamento devem ser analisados, para que se possa ter uma idéia real do ajuste do modelo. 
Quando analisadas as medidas dos índices GFI, AGFI, TLI e CFI, percebe-se que ficaram sempre acima de 0,90, conforme o recomendado por Hair et al. (1998) e Kline (1998). A medida de ajuste RSMEA possui valores aceitáveis entre 0,05 e 0,08 (Hair et al.,1998). Analisando-se os dados acima, observa-se que as dimensões de propensão à recomendação e recompra, surpresa positiva e personalização, obtiveram valores acima do aceitável para o referido índice. Esse índice, entretanto, compartilha a mesma natureza teórica que o CFI, segundo Raykov e Marcoulides (2000). Dessa forma, devido aos valores elevados do CFI obtidos nas dimensões analisadas, essas foram consideradas validadas também. Deve-se considerar, ainda, que a existência de apenas três ou dois indicadores nas dimensões que apresentaram os índices impróprios pode ser uma razão para a ocorrência desses índices, devendo o número de indicadores ser revisto em estudos futuros.

Posto isso, a unidimensionalidade foi atingida através do exame dos resíduos padronizados, que poderiam indicar itens com ajuste inaceitável para com o modelo (Garver \& Mentzer, 1999; Jöreskog \& Sörbom, 1982; Steenkamp \& Trijp, 1991). Segundo os autores, para que uma dimensão possua unidimensionalidade é necessário que todos os seus resíduos padronizados sejam inferiores a 2,58. A maior carga residual padronizada encontrada no estudo foi de 2,049 na dimensão de personalização, podendo-se, assim, conferir unidimensionalidade a todas as dimensões da escala.

As medidas de confiabilidade utilizadas em equações estruturais buscam suplantar as limitações associadas ao coeficiente Alfa de Cronbach (Dunn et al., 1994; Garver \& Mentzer, 1999; Steenkamp \& Trijp, 1991). Dessa forma, foram utilizados, para a mensuração da confiabilidade, os valores da confiabilidade composta e variância extraída. Segundo os autores citados, são aceitos valores iguais ou superiores a 0,70 , para a confiabilidade composta, e 0,50, para variância extraída, que mede a quantidade total de variância dos indicadores computada pela variável latente (Garver \& Mentzer, 1999). Para Fornell e Larcker (1981), se menos de 0,50 da variância do erro de mensuração é capturada pelo constructo, a validade dos indicadores individuais, assim como a do constructo, é questionável. Assim, a Tabela 4 apresenta os valores da confiabilidade composta e variância extraída para todas as dimensões do constructo, aferindo a sua confiabilidade.

De acordo com Dunn et al. (1994), Garver e Mentzer (1999) e Bagozzi et al. (1991) a validade convergente de uma escala é dada pela qualidade de suas medidas de ajustamento. Ainda que todas as dimensões do constructo tenham sido validadas através do exame de suas medidas de ajustamento, dando suporte à validade convergente da escala proposta, procedeu-se também à sua verificação 
por outros critérios, para que se pudesse ter certeza acerca de sua inferência para as dimensões da escala.

Nesse sentido, Dunn et al. (1994) afirmam que, se as cargas individuais dos indicadores que representam uma variável latente são estatisticamente significantes, então pode-se inferir a existência de validade convergente. A significância das medidas individuais dos indicadores pode ser dada através do exame dos $t$-values, sendo que valores acima de $|2,0|$ são considerados significantes em nível de 0,05 (Bagozzi et al., 1991). Steenkamp e Trijp (1991) assinalam ainda a necessidade da correlação entre cada indicador e a variável latente (que representa a carga fatorial padronizada) ser igual ou superior a 0,50 para a aferição da validade convergente. Ambos os pré-requisitos foram levados em consideração neste estudo e, como pode ser observado na Tabela 4 abaixo, as especificações para a confirmação da validade convergente foram atingidas.

Tabela 4: Indicadores de Confiabilidade e Validade Convergente

\begin{tabular}{ccccc}
\hline & \multicolumn{2}{c}{ Confiabilidade } & \multicolumn{2}{c}{ Validade Convergente } \\
\hline Dimensões & $\begin{array}{c}\text { Confiabilidade } \\
\text { Composta }\end{array}$ & $\begin{array}{c}\text { Variância } \\
\text { Extraída }\end{array}$ & $\begin{array}{c}\text { Menor Carga } \\
\text { Fatorial Padronizada }\end{array}$ & Menor t-value $^{*}$ \\
\hline Aspectos Afetivos & 0,974936 & 0,687991 & 0,591 & 10,042 \\
Aspectos Cognitivos & 0,960948 & 0,629608 & 0,614 & 8,863 \\
Propensão à Recomendação & 0,967282 & 0,688755 & 0,561 & 13,343 \\
e Recompra & 0,969538 & 0,71218 & 0,598 & 9,426 \\
Surpresa Positiva & 0,964825 & 0,640634 & 0,707 & 11,567 \\
Personalização &
\end{tabular}

*t-values não calculados para itens com carga fatorial arbitrada em 1.

Como último procedimento para aferir a validade de constructo, foi verificada a validade discriminante. Para que exista validade discriminante entre as dimensões do constructo estudado, deve-se certificar se as escalas desenvolvidas para mensurar as diferentes dimensões do constructo estão de fato mensurando as dimensões a que se propõem (Garver \& Mentzer, 1999).

Dentre os métodos existentes para o cálculo da validade discriminante, optouse por aquele proposto por Fornell e Larcker (1981). O método propõe que a variância extraída para cada dimensão deve ser maior que o quadrado da correlação entre a dimensão e qualquer outra dimensão, o que caracteriza a variância compartilhada. Se, para cada uma das dimensões, a variância extraída é maior que a variância compartilhada, é confirmada a validade discriminante. Caso contrário, a maior parte da variância da dimensão está compartilhada com outras dimensões, não podendo ser atribuída à validade discriminante. Para o constructo estudado, encantamento do cliente, foi verificada validade discriminante dentre as dimensões, conforme pode ser observado pela 
demonstração na Tabela 5, quando a variância extraída, destacada na diagonal em negrito, é percebida como maior que a variância compartilhada entre as dimensões, representada pelos demais valores presentes na tabela.

\section{Tabela 5: Indicadores de Validade Discriminante}

\begin{tabular}{cccccc}
\hline & $\begin{array}{c}\text { Aspectos } \\
\text { Afetivos }\end{array}$ & $\begin{array}{c}\text { Aspectos } \\
\text { Cognitivos }\end{array}$ & $\begin{array}{c}\text { Propensão à Recom. } \\
\text { e Recompra }\end{array}$ & $\begin{array}{c}\text { Surpresa } \\
\text { Positiva }\end{array}$ & Personalização \\
\hline Aspectos Afetivos & $\mathbf{0 . 6 8 8 0}$ & & & & \\
Aspectos Cognitivos & 0.1840 & $\mathbf{0 . 6 2 9 6}$ & & & \\
Propensão à Recomendação e & 0.1096 & 0.2746 & $\mathbf{0 . 6 8 8 8}$ & & \\
Recompra & & & & & \\
Surpresa Positiva & 0.2788 & 0.3600 & 0.1832 & $\mathbf{0 . 7 1 2 2}$ & \\
Personalização & 0.0581 & 0.0807 & 0.0000 & 0.0640 & $\mathbf{0 . 6 4 0 6}$ \\
\hline
\end{tabular}

A percepção da existência de validade discriminante para a escala estudada, juntamente com a confirmação da existência dos ajustes favoráveis dos modelos, de unidimensionalidade, de confiabilidade e de validade convergente confirmam o processo de auferição de validade e de confiabilidade à escala proposta.

\section{Considerações Finais}

O objetivo dos projetos de pesquisa, segundo Gerbing e Anderson (1988, p.191), não é apenas "desenvolver escalas de mensuração unidimensionais e confiáveis, mas construir e testar teoria". Dentro desse contexto, a construção e o teste de escala, realizados neste trabalho, vêm ao encontro da necessidade de desenvolvimento de uma maior compreensão teórica acerca do encantamento do cliente.

Assim, a primeira evidência, acerca do estudo, pode ser descrita como a relevância da purificação de medidas, através de sucessivas reaplicações da escala, pois somente a evidência empírica pôde comprovar que alguns itens, ou até dimensões inteiras, como a de preço, não faziam parte do constructo. É importante notar que, no decorrer dos três estudos aqui desenvolvidos, foram adotados não apenas processos de refinamento da escala, com a retirada de itens da estrutura fatorial, mas também processos de adaptação da estrutura dela, através da mudança da escrita de alguns itens, para melhor compreensão e interpretação por parte dos respondentes. Nesse sentido, é importante saber que os resultados das EFA foram, algumas vezes, submetidos à análise de conteúdo, para que não se cometessem erros de purificação (Rossiter, 2002). Segundo Finn e Kayande (2004), este método tem tido melhor impacto na performance de escalas do que os processos de refino tradicionais. 
Dessa maneira, tem-se como contribuição e implicação para a academia de marketing a confirmação das dimensões que compõem o constructo encantamento do cliente, através dos ajustes favoráveis dos modelos e da confirmação da existência de unidimensionalidade, de confiabilidade e de validade para a escala proposta em todas as dimensões analisadas, o que confirma a validade de seu constructo. A validade de conteúdo também foi atingida devido à qualidade dos itens de mensuração, assim como devido às suas sucessivas purificações. Ainda assim, encoraja-se a aplicação da escala em novos contextos e com outra população, suprindo as deficiências que possam ter feito parte deste estudo, como a utilização da amostra de estudantes, dadas as limitações de validade externa decorrentes desse tipo de amostragem.

Quando se avalia o objeto de pesquisa utilizado pelos respondentes, percebe-se a supremacia da menção a produtos em detrimento de serviços nos três estudos realizados. Causas para este fenômeno ainda não foram encontradas. AANOVA, realizada no terceiro estudo, denota, entretanto, que quando há diferenças estatisticamente significativas nas médias entre consumidores de produtos e de serviços as médias do último grupo são sempre significativamente maiores. Enfatizase, assim, a importância da inserção da variabilidade dos serviços a produtos que são geralmente padronizados, dada a sua necessidade, quando se busca entregar performance prazerosamente inesperada (Oliver et al., 1997). Daí o importante papel desempenhado pelas variáveis que buscam mensurar a dimensão de personalização atinente ao constructo.

Outra questão a se considerar é a conclusão de que as variáveis de percepção de preço não são uma dimensão do encantamento do cliente, conforme se pressupunha. Assim, a percepção de preço baixo ou preço justo só faz parte do encantamento do cliente, quando esta for acompanhada de algum outro atributo que também tenha a capacidade de encantar (ex.: 'a calça ficou perfeita e ainda era barata' - depoimento de respondente na fase qualitativa). $O$ fato de a calça ser somente barata não encanta, apenas satisfaz no quesito barganha ou eqüidade. A existência do encantamento pressupõe que a experiência tenha outros componentes que possam efetivamente gerar afeto positivo e surpresa no consumidor.

Dessa forma, embora ainda sejam necessários novos estudos para confirmar o real papel acessório do preço na formação do encantamento, deve-se ter cuidado, quando se pretende utilizá-lo com a finalidade de encantar clientes. Essa constatação é importante para as organizações perceberem que o encantamento deve dar-se com atributos diferenciadores da companhia e não por estratégias facilmente imitáveis pela concorrência, como promoções por preço. A incapacidade de ser copiada é condição necessária para as empresas que buscam o verdadeiro encantamento do cliente (Rust \& Oliver, 2000). 
Por fim, sugere-se a inclusão do encantamento, através da escala proposta, em modelos teóricos acerca do processo de avaliação pós-consumo, o que permitirá avaliar com maior profundidade os impactos distintos entre satisfação e encantamento do cliente em resultados comportamentais posteriores. O teste do modelo teórico completo também é um passo a ser dado, visto que poderá levar à compreensão das relações existentes entre as dimensões da escala e a verificação de quais antecedentes do constructo têm maior impacto em comportamentos subseqüentes, como recomendação e recompra. Outras relações que busquem maior compreensão do papel do encantamento do cliente na avaliação pós-consumo também devem ser empiricamente verificadas, buscando uma visão mais abrangente do encantamento do cliente, como resultado emocional altamente positivo na experiência de consumo.

\section{Artigo recebido em 03.11.2004. Aprovado em 18.04.2005.}

\section{ReferênCIAS BibliográficAs}

Anderson, E. (1998).

Customer satisfaction and word of mouth. Journal of Service Research, 1(1), 5-17.

Astic, G., \&

Muller, T.E. (1999).

Delighting the senior tourist. Journal of Consumer Satisfaction, Dissatisfaction and Complaining Behavior, 12, 71-80.

Bagozzi, R. P.,

Yi, Y., \&

Philips, L. W. (1991).

Assessing construct validity in organizational research. Administrative Science Quarterly, 36(3), 421-458.

Biyalogorsky, E.,

Gerstner, E., \&

Libai, B. (2001).

Customer referral management: optimal reward programs. Marketing Science, 20(1), 82-95.
Churchill, G. A., Jr. (1979).

A paradigm for developing better measures of marketing constructs. Journal of Marketing Research, 16(1), 64-73.

Derbaix, C., \&

Vanhamme, J. (2003).

Inducing word-of-mouth by eliciting surprise - a pilot investigation. Journal of Economic Psychology, 24(1), 99-116.

DeVellis, R. F. (1991).

Scale development: theory and applications. Newbury Park: Sage.

Dunn, S. C.,

Seaker, R. F., \&

Waller, M. A. (1994).

Latent variables in business logistics research: scale development and validation. Journal of Business Logistics, 15(2), 145-172. 
Finn, A., \&

Kayande, U. (2004).

Scale modification: alternative approaches and their consequences. Journal of Retailing, 80(1), 37-52.

Fornell, C., \&

Larcker, D. F. (1981).

Evaluating structural equation models with unobservable variables and measurement error. Journal of Marketing Research, 23(1), 39-50.

Garver, M. S., \&

Mentzer, J. T. (1999).

Logistics research methods: employing structural equation modeling to test for construct validity. Journal of Business Logistics, 20(1), 33-57.

Gerbing, D. W., \&

Anderson, J. (1988).

An updated paradigm for scale development incorporating unidimensionality and its assessment. Journal of Marketing Research, 25(2), 186-192.

Hair, J. F. J.,

Anderson, R. E.,

Tatham, R. L., \&

Black, W. C. (1998).

Multivariate data analysis. New Jersey, EUA: Prentice Hall.

Izard, C. E. (1977).

Human emotions. New York: Plenum.

Jöreskog, K. G., \&

Sörbom, D. (1982).

Recent developments in structural equation modeling. Journal of Marketing Research, 19(4), 404-416.
Keiningham, T., \&

Vavra, T. (2001).

The customer delight principle. New York: McGraw-Hill - American Marketing Association.

Kline, R. B. (1998).

Principles and practice of structural equation modeling. New York: The Guilford Press.

Kumar, A. (1996).

Customer delight: creating and maintaining competitive advantage. Tese de doutorado, Graduate Faculty, Indiana University, Indiana, EUA.

Mano, H. (1997).

Affect and persuasion: the influence of pleasantness and arousal on attitude formation and message elaboration. Psychology and Marketing, 14(4), 315-335.

Mano, H., \&

Oliver, R. L. (1993).

Assessing the dimensionality and structure of consumption experience: evaluation, feeling and satisfaction. Journal of Consumer Research, 20(3), 451-466.

Oliver, R. L. (1997).

Satisfaction: a behavioral perspective on consumer. New York: McGraw-Hill.

Oliver, R. L.,

Rust, R. T., \&

Varki, S. (1997).

Customer delight: foundations, findings, and managerial insight. Journal of Retailing, 73(3), 311-336. 
Oliver, R. L., \&

Westbrook, R.A. (1993).

Profiles of consumer emotions and satisfaction in ownership and usage. Journal of Consumer Satisfaction, Dissatisfaction and Complaining Behavior, 6, 12-27.

Peter, J. P. (1981).

Construct validity: a review of basic issues and marketing practices. Journal of Marketing Research, 18(2), 133-145.

Plutchik, R. (1980).

Emotion: a psychoevolutionary synthesis. New York: Harper \& Row.

Raykov, T., \&

Marcoulides, G. A. (2000).

A first course in structural equation modeling. New Jersey: Lawrence Erlbaum Associates.

Rossiter, J. R. (2002).

The C-OAR-SE procedure for scale development in marketing. International Journal of Research in Marketing, 19(4), 305-335.
Russell, J. A. (1980).

A circumplex model of affect. Journal of Personality and Social Psychology, 39(6), 1161-1178.

Rust, R. T., \&

Oliver, R. L. (2000).

Should we delight the customer? Journal of the Academy of Marketing Science, 28(1), 86-94.

Steenkamp, Jan-B. E. M., \&

Trijp, H. C. M. van (1991).

The use of LISREL in validating marketing constructs. International Journal of Research in Marketing, 8(4), 283-299.

Vanhamme, J. (2002).

The influence of the emotion of surprise on consumer's satisfaction: a pilot experiment. Proceedings of the Conference of European Marketing Academy - EMAC, Braga, Portugal, 31.

Westbrook, R. A., \&

Oliver, R. L. (1991).

The dimensionality of consumption emotions patterns and consumer satisfaction. Journal of Consumer Research, 18(1), 84-91. 